\title{
Medical Thermography to assess the Degree of Inflammation in Painful Joints and Muscles
}

Dott Catello Matonti*

Expert in natural medicine, magnetotherapy and medical thermography, Fiorignano - Battipaglia (SA), Italy

Submission: November 13, 2019; Published: November 25, 2019

*Corresponding author: Dott Catello Matonti, expert in natural medicine, magnetotherapy and medical thermography, Fiorignano - Battipaglia (SA), Italy

\section{Introduction}

Medical thermography also allows us to assess defects in superficial and deep venous circulation. It is performed on ambulatory patients in order to choose the type of magnetotherapy (static field - high frequency - low frequency) useful for the resolution of the pathology. Medical thermography has no contraindication

\section{Clinical Images}

Figures (1 to 8)

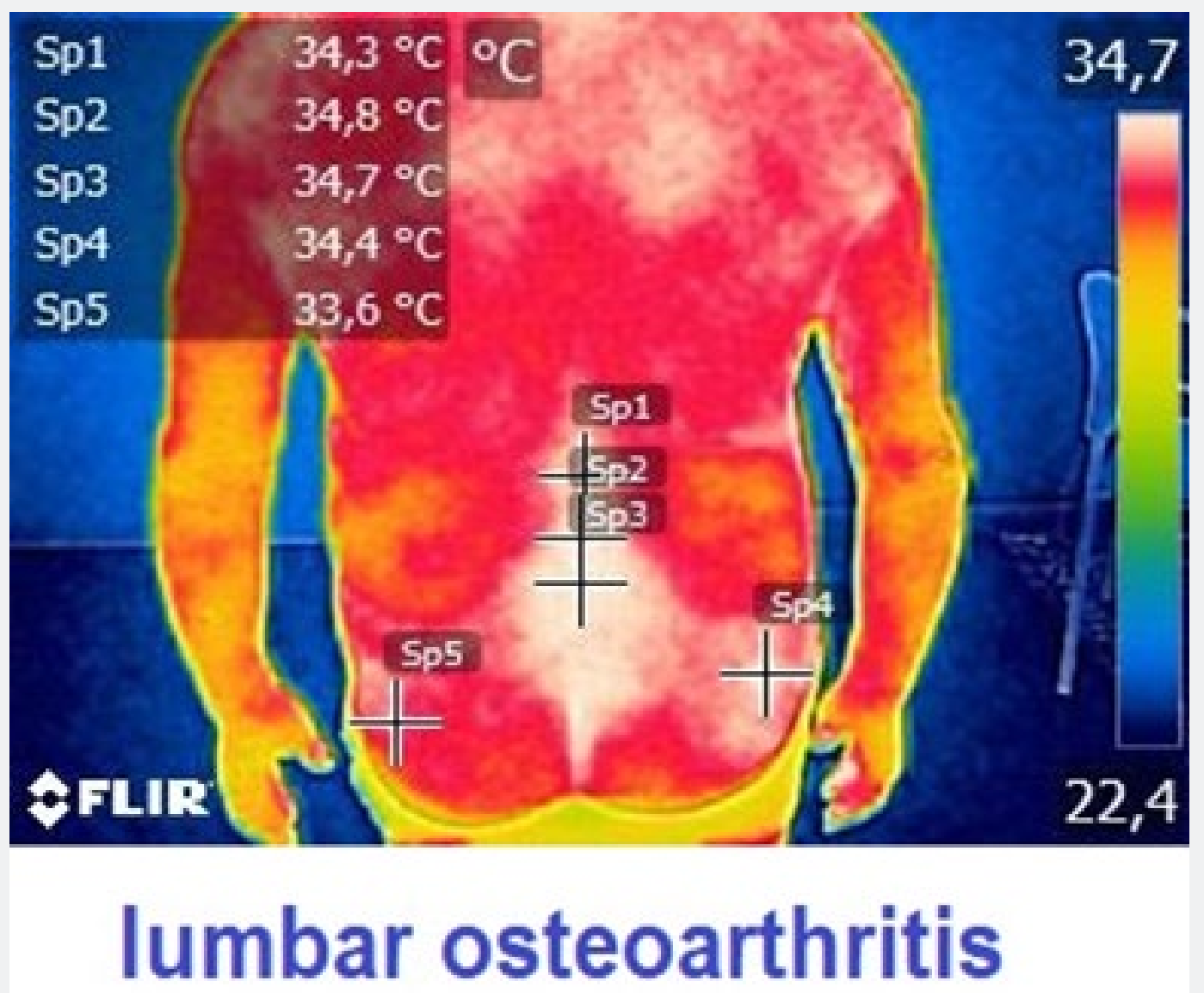

Figure 1: Medical thermography performed on a 57 -year-old male patient with right sciatica secondary to herniated disc $14 \mathrm{~s} 5$. Lumbar band treatment with static field magnets for at least 8 hours during the day. 


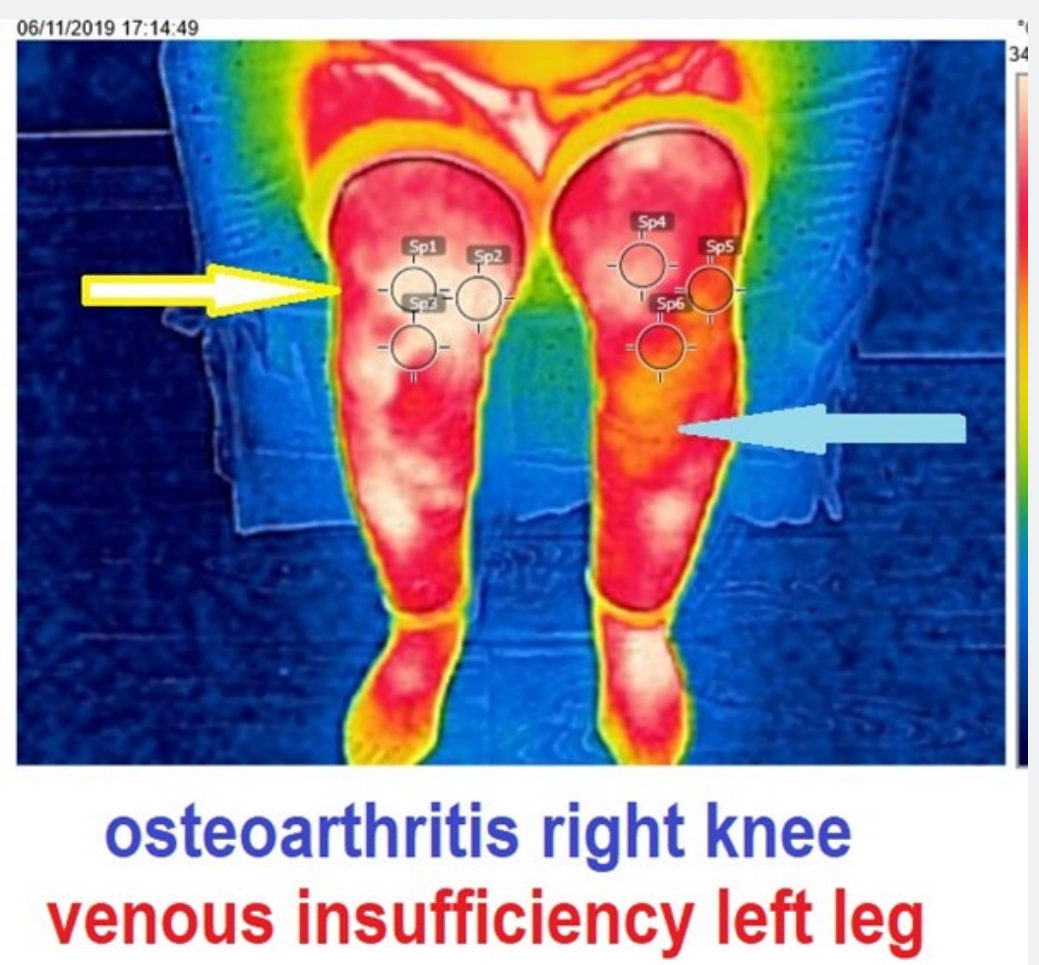

Figure 2: Medical thermography performed on an 81-year-old female patient with right gonarthrosis and venous insufficiency of the left leg. Knee brace with static field magnets for at least 6 hours during the day. Knee-sock in bio ceramic fabric active in the infrared far to the left leg.

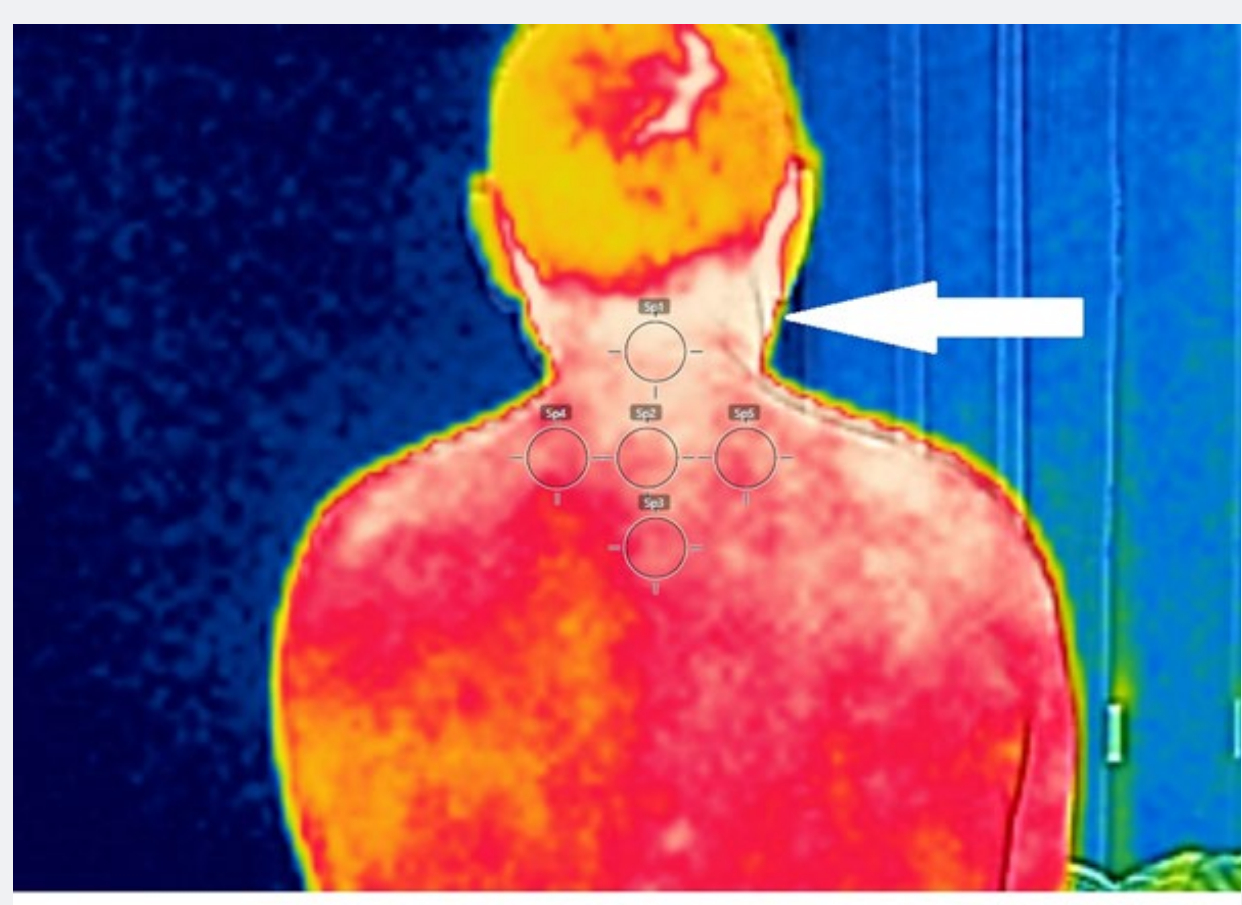

\section{cervicalgia from herniated disc}

Figure 3: Medical thermography performed on a 39-year-old male patient with acute cervicalgia secondary to c3-c4 herniated disc. Collar treatment with static field bio magnets to be used at night for at least 6 hours. 


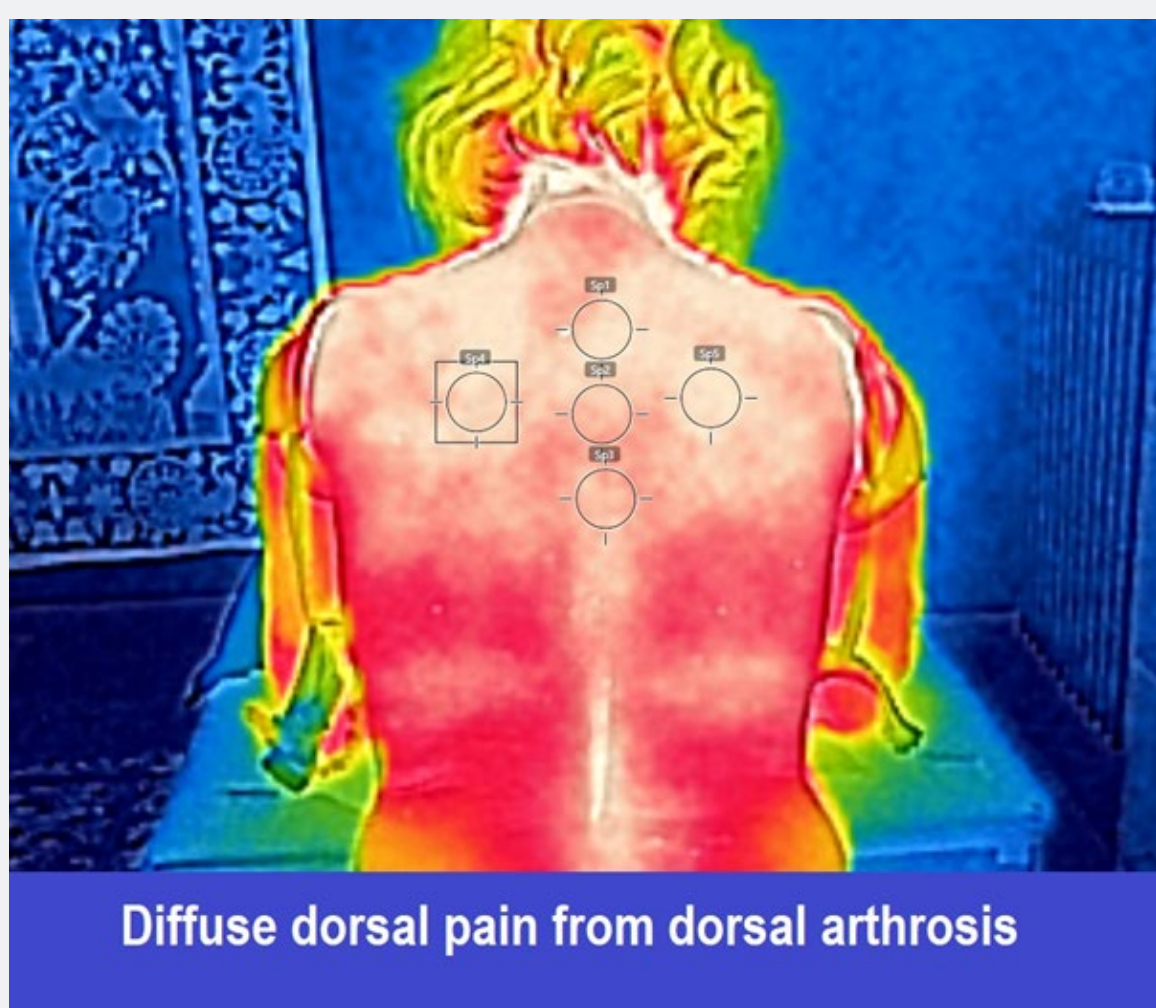

Figure 4: Medical thermography performed on a 48-year-old female patient suffering from dorsal arthrosis with disc protrusions. The patient complains of back pain on walking and in bed. Treatment with low frequency magnetotherapy with $80 \mathrm{hz}$ and 90 gausses using the negative polarity.

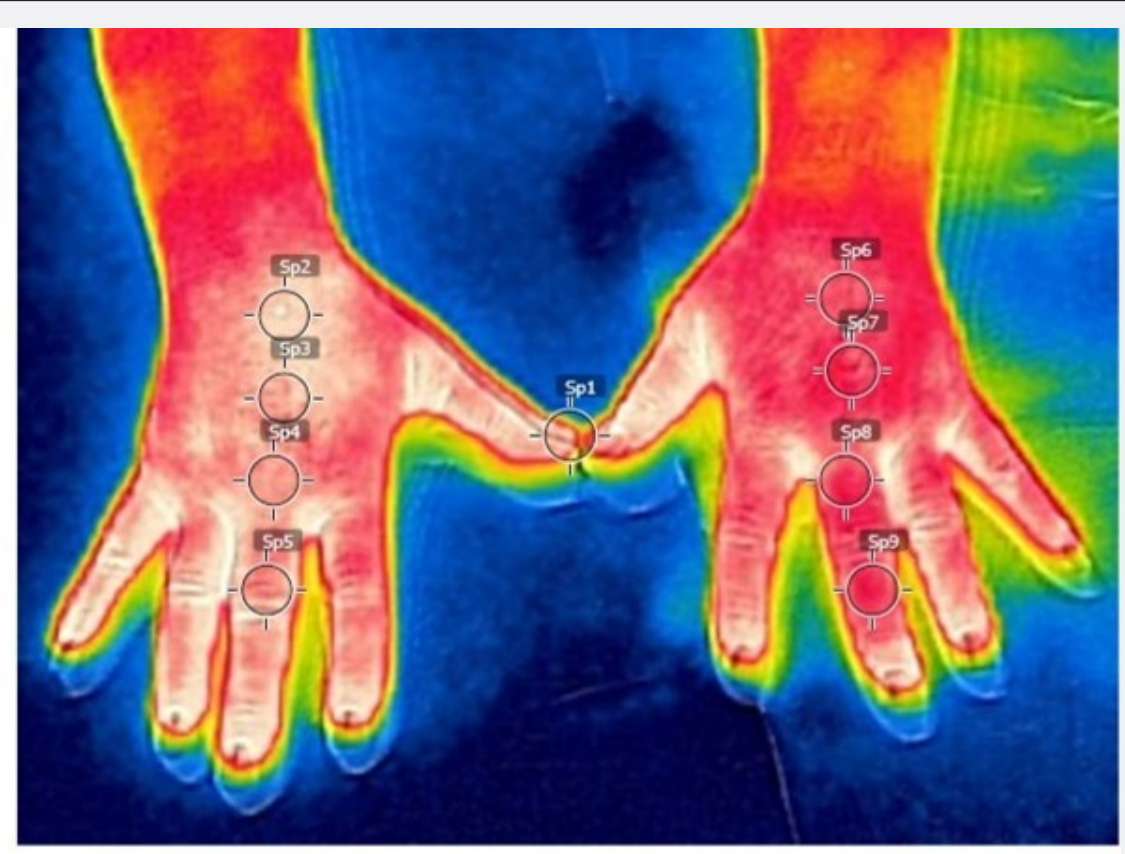

\section{right hand rheumatic arthritis}

Figure 5: Thermography performed on a 51-year-old female patient with rheumatic arthritis in her right hand. He feels intense pain on his wrist and especially on his ring finger. Therapy with static field magnets and high frequency scanning magnetotherapy cycles from 500 to $5000 \mathrm{hz}$. 


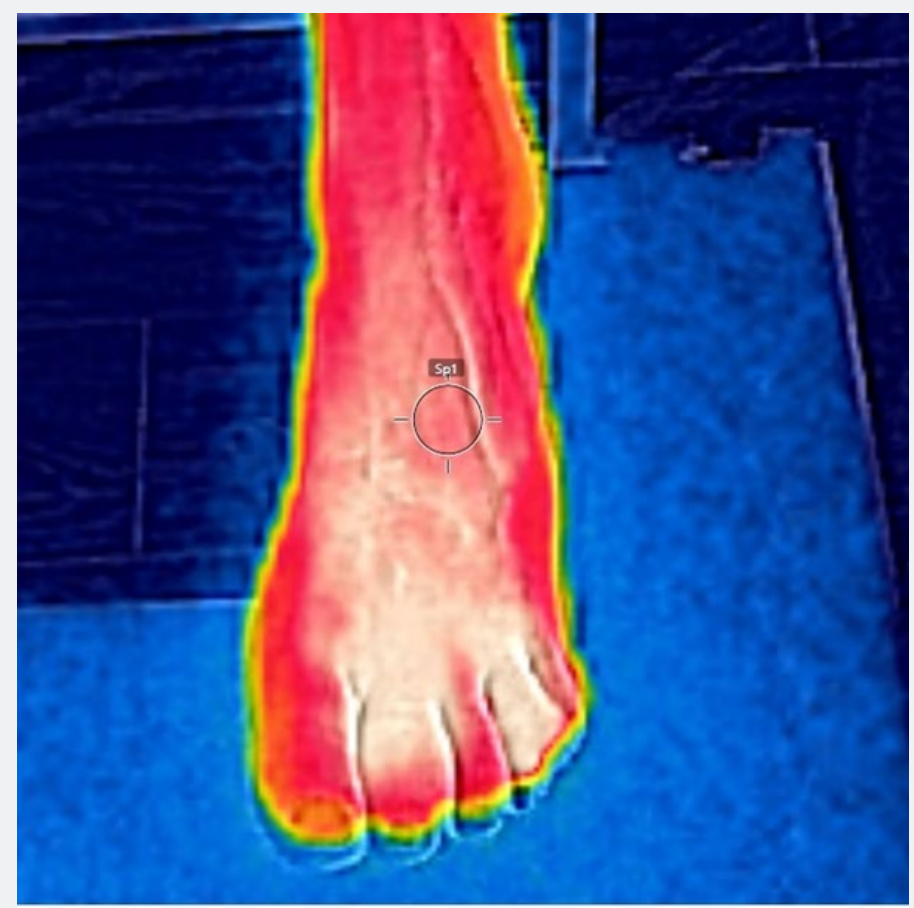

\section{gouty arthritis}

Figure 6: Thermography performed on a 55-year-old male patient with gouty arthritis right foot. Intense pain on the second and fourth toes. Treated with static field magnetotherapy.

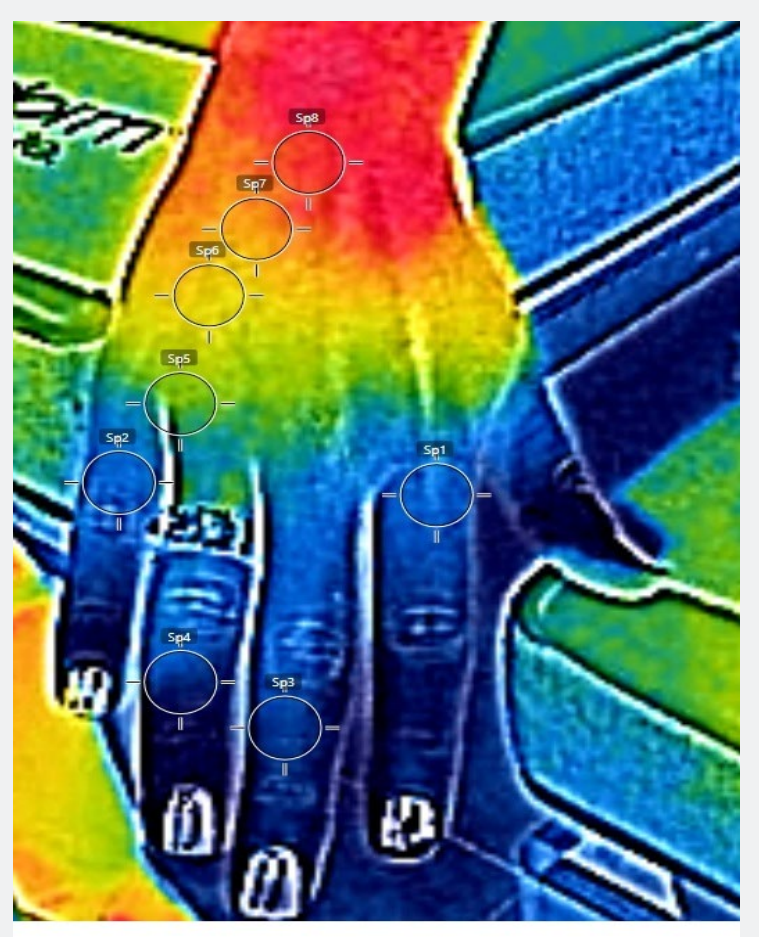

\section{Raynaud's syndrome}

Figure 7: Medical thermography performed on a 31-year-old female patient suffering from Raynaud's syndrome with right hand circulatory deficit. Treatment with a glove in active infrared bio ceramics and high frequency magnetotherapy for 6 hours at night. 


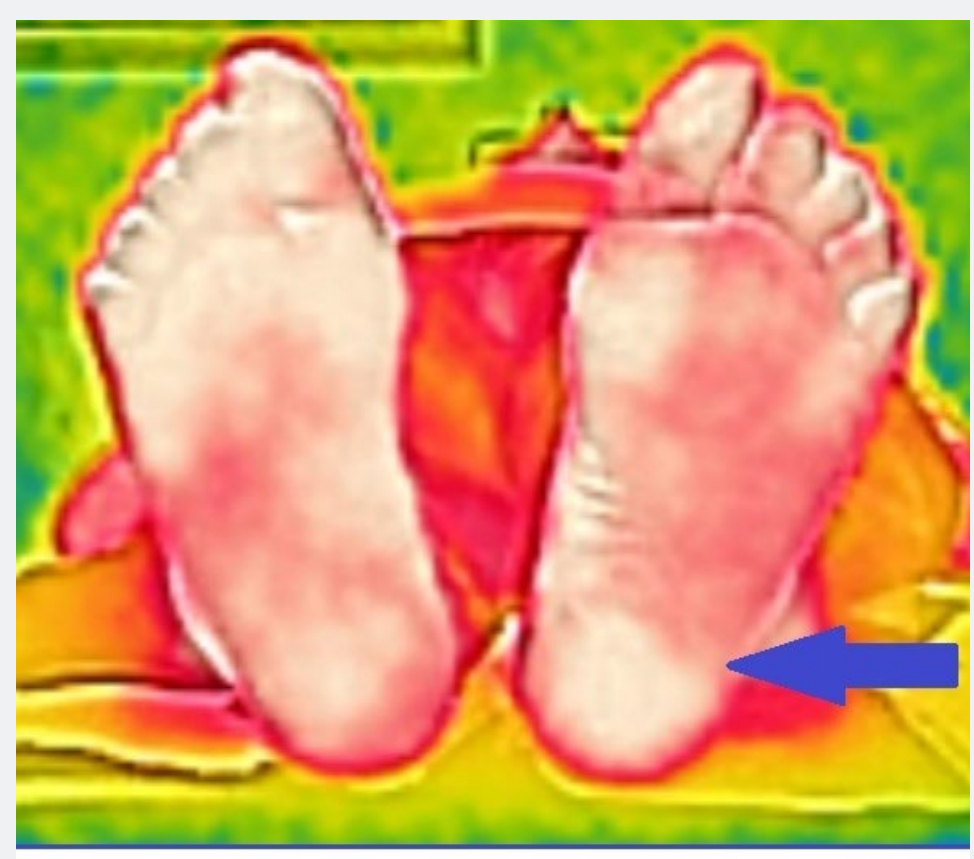

\section{heel spur}

Figure 8: Medical thermography performed on a 62-year-old male patient with heel spur left foot. Treatment with insole with static field bio magnets to be used during walking.

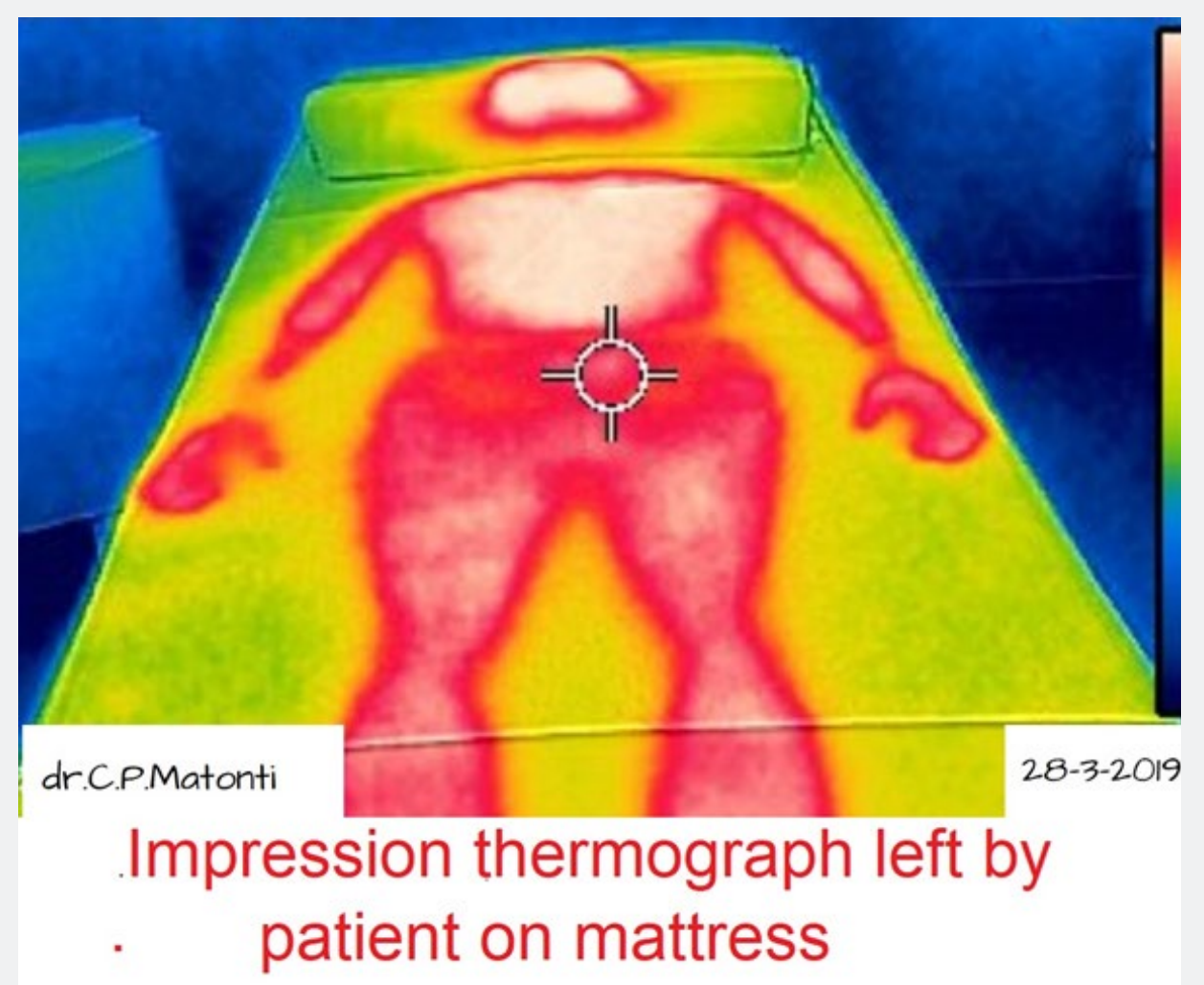

Figure 9: Thermographic impression on the mattress to assess the correct resting posture. 
Your next submission with Juniper Publishers will reach you the below assets

- Quality Editorial service

- Swift Peer Review

- Reprints availability

- E-prints Service

- Manuscript Podcast for convenient understanding

- Global attainment for your research

- Manuscript accessibility in different formats ( Pdf, E-pub, Full Text, Audio)

- Unceasing customer service

Track the below URL for one-step submission https://juniperpublishers.com/online-submission.php 